This item was submitted to Loughborough's Research Repository by the author.

Items in Figshare are protected by copyright, with all rights reserved, unless otherwise indicated.

\title{
Innovation in cleaner production through waste recycling in composites
}

PLEASE CITE THE PUBLISHED VERSION

http://dx.doi.org/10.1108/14777831311291104

PUBLISHER

(c) Emerald Group Publishing Limited

VERSION

AM (Accepted Manuscript)

LICENCE

CC BY-NC-ND 4.0

REPOSITORY RECORD

Osmani, Mohamed. 2019. "Innovation in Cleaner Production Through Waste Recycling in Composites". figshare. https://hdl.handle.net/2134/13396. 
This item was submitted to Loughborough's Institutional Repository (https://dspace.lboro.ac.uk/) by the author and is made available under the following Creative Commons Licence conditions.

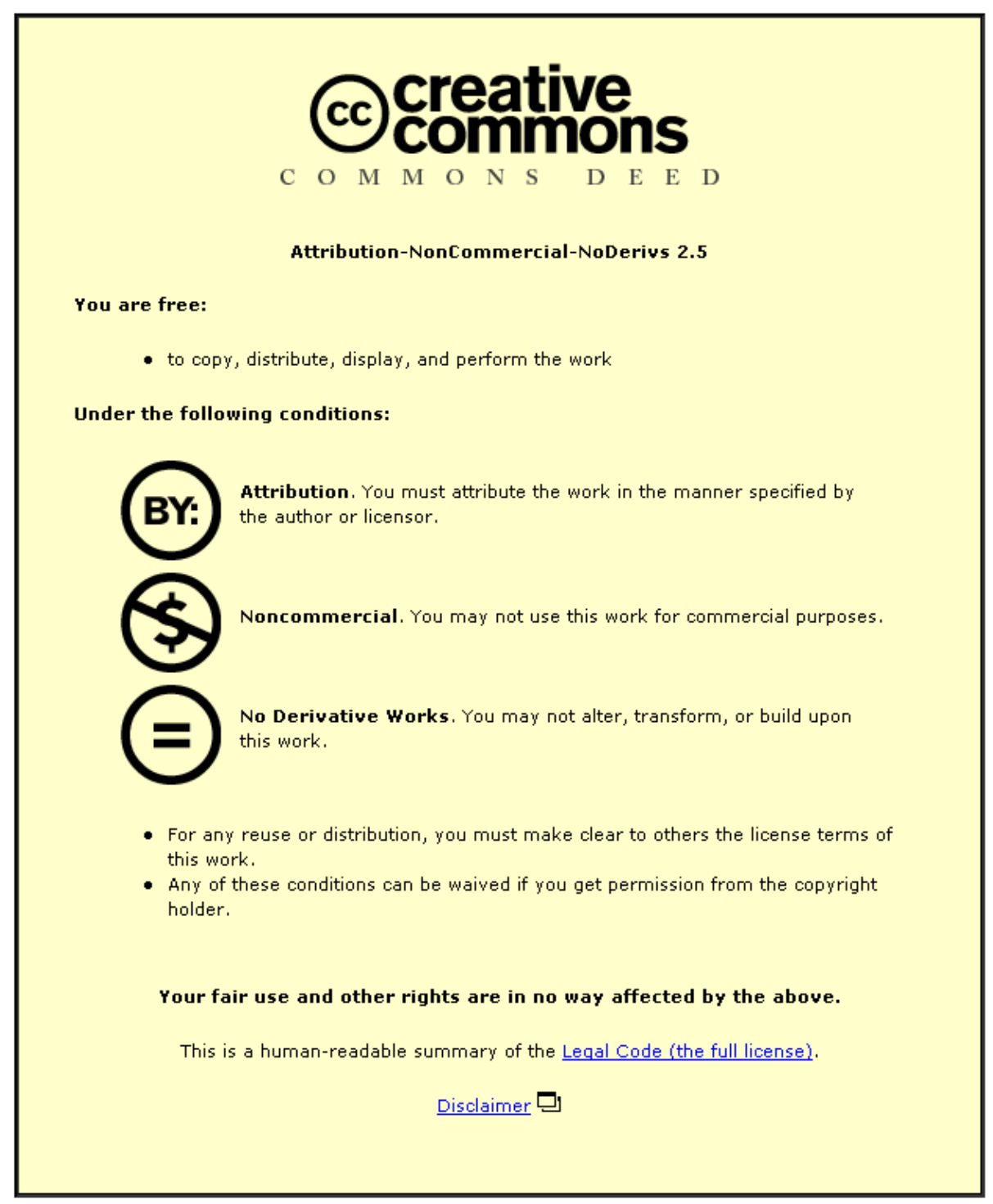

For the full text of this licence, please go to: http://creativecommons.org/licenses/by-nc-nd/2.5/ 


\title{
Innovation in cleaner production through waste recycling in composites
}

\begin{abstract}
Purpose - At present Glass Reinforced Plastic (GRP) waste recycling is very limited due to its intrinsic thermoset composite nature and non-availability of viable recovery options. The aim of this research is to assess the recycling potential of GRP waste powder and fibre in concrete, cement and rubber composites.
\end{abstract}

Design/methodology/approach - Extensive laboratory experiments were conducted to examine the suitability of GRP waste in concrete, cement, and rubber composites. GRP waste samples were processed and suitable tests were performed to measure the mechanical properties of the resulting three composites.

Findings - The findings of this experimental investigation confirmed that GRP waste can be used as a partial replacement for virgin and raw materials in composites. Furthermore, the addition of GRP waste powder and fibre to composites has the potential to improve their mechanical properties.

Research limitations/implications - Results show that the use of GRP waste powder in concrete and rubber composites and GRP waste fibre in architectural cladding panels has technical, economic and environmental benefits. As such, the findings of this research pave the way for viable technological options for substituting quality raw materials by GRP waste in pan-industry composites and improving their mechanical properties. However, resulting recycled composites depend upon the consistency and quality of GRP waste powder and fibre, and the access to specialised composite material manufacturing facilities. Furthermore, full compliance tests including durability studies and requirements, which may depend upon specific applications, are recommended.

Practical implications - The adopted methodological approach of this research and subsequent experimental results pave the way for viable technological options for substituting quality raw materials by GRP waste in pan-industry composites. It is anticipated that the results of this research would help diverting GRP waste from landfill to more useful industrial applications.

Originality/value - Growing technological innovations, ample market value and demand for GRP composites all over the world has trigged interest in optimising GRP waste recovery. However; few solutions for GRP waste recycling into value-added industrial products are being explored. The work reported so far is very limited and did not show viable applications for GRP waste composites. Hence, this research sets out to examine the suitability of GRP waste powder and fibre in concrete, cement, and rubber composites.

Keywords: GRP waste, Recycling, Concrete composites, Cement composites, Rubber composites, Landfill diversion.

\section{Introduction}

Glass Reinforced Plastic (GRP) is increasingly being used in consumer and building products due to its low weight, durability, versatility and wear and corrosion resistance. However, the effective disposal of GRP waste is a significant challenge worldwide. GRP waste is a rejected product due to various damages, imperfections, and is often discarded during the manufacturing process of GRP industries. Reliable figures on GRP composite waste volumes are not available; however it has been reported that an estimated 150,000 tonnes are currently produced each year in the 
Osmani, M. (2013) Innovation in cleaner production through waste recycling in composites, Management of Environmental Quality, 24(1), pp.1-9.

United Kingdom (Ord, 2011). Landfill and incineration are the most commonly practiced disposal methods accounting for more than 90\% of GRP waste (Conroy et al, 2006). Therefore, effective management and safe disposal of GRP waste has become one of the prime concerns in the United Kingdom where the landfill cost for waste disposal is expected to reach $£ 64$ per tonne by April 2012.

It was reported that the use of GRP waste ground fibre, as replacement for fine aggregate in foamed concrete, increased strength with reduced weight (Gemert et al, 2005). Moreover, the latter study revealed that the fire resistant properties of GRP filled foamed concrete were suitable for structural and semi-structural applications in lightweight partitions, wall and floor panels. A study on GRP waste recycling showed that glass fibres recovered from polymeric chemicals could replace up to $20 \%$ of the virgin glass fibres used in dough moulding compound (Jo et al, 2008). Virgin glass fibre has been used in making thin sheets of flat, corrugated or complex shaped panels as precast concrete products for construction (Broekel and Scharr, 2005). Studies on GRP waste recycling revealed that the ground glass fibres removed from granules were used with wood flour in high density polyethylene (HDPE) to increase tensile and flexural modulus (Khan, 2007). However, the polymeric compound and glass fibre in GRP waste still needs to find recovery alternatives. Attempts were also made to recycle concrete and masonry materials along with unsaturated polyester resins and polyethylene terephthalate (PET) plastic waste and reported that the resin addition increased the strength of polymer concrete (Jones et al, 2005). Moreover, the acid and alkali elements were found not to affect the polymer concrete. Efforts were also made to characterise the properties of recycled glass fibre reinforced polymide (Ansarifar et al, 2010), but the suitability and their recycling potentials are not yet well established (Bentur and Mindess, 1990).

Growing technological innovations, ample market value and demand for GRP composites all over the world has trigged interest in optimising GRP waste recovery; however, few solutions for its recycling into value-added industrial products are being explored. The work reported so far is very limited and did not show viable applications for GRP waste composites. Consequently in the present study, efforts were made to recycle ground GRP waste powder and fibre in composites.

\section{Methodology}

An experimental methodology was adopted for this study to assess the potential of GRP waste recycling in composites; three comprehensive sets of laboratory testing programmes were conducted. Attempts were made to recycle GRP waste powder as a proportional substitute to fine aggregate in concrete composites on the one hand, and replacement of natural rubber in rubber composites on the other. Additionally, GRP waste fibres were used as structural reinforcement materials in architectural cladding panels.

The GRP waste samples were obtained from Hambleside Danelaw Rooflights and Cladding Limited, Scotland, which consisted of a mixture of ground powder and fibre. As shown in Figure 1, the GRP waste sample was processed using $2 \mathrm{~mm}$ sieve, resulting in $95 \%$ powder and $5 \%$ fibre. 
Osmani, M. (2013) Innovation in cleaner production through waste recycling in composites, Management of Environmental Quality, 24(1), pp.1-9.

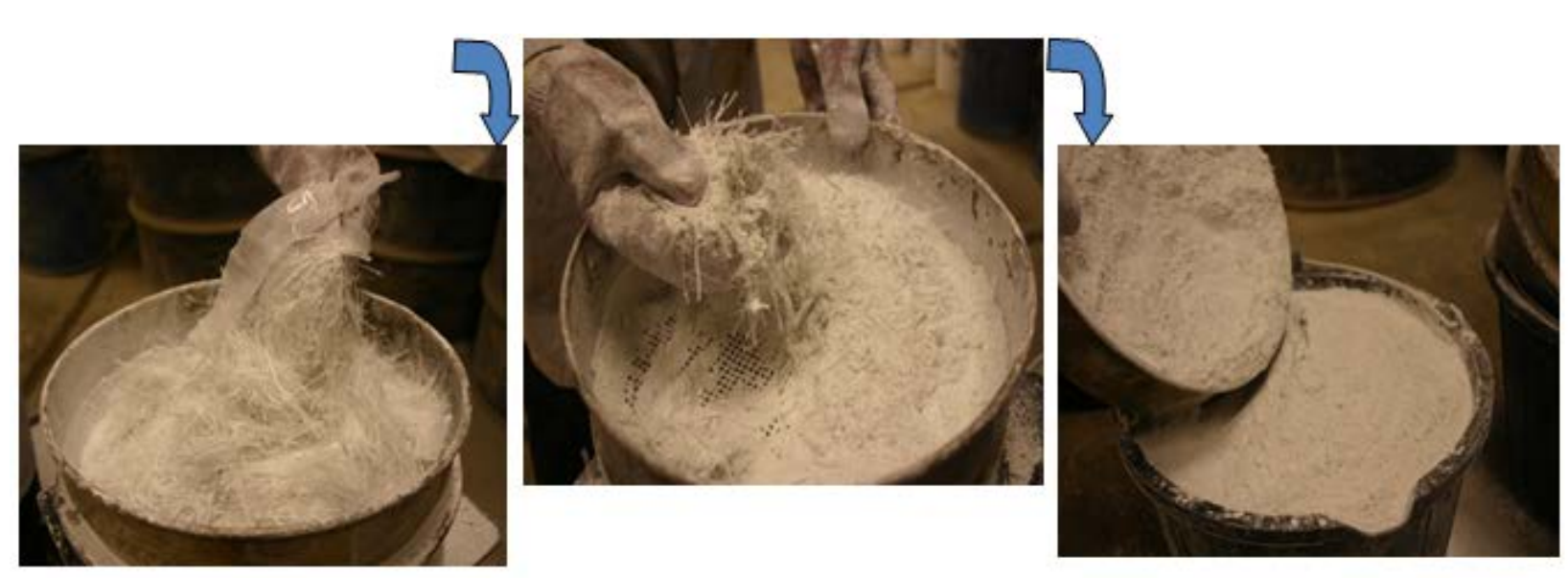

Figure 1: Glass Reinforced Plastic (GRP) waste sample processing

\subsection{GRP waste-concrete composite experimental programme}

Detailed experiments were conducted on the use of GRP waste powder in concrete composites. Mix design was performed in accordance with Building Research Establishment (BRE) $1988 \mathrm{mix}$, and concrete specimens were prepared as per BS EN 12390-2:2000 using different proportions of cement, aggregate, and GRP waste. Processed GRP waste powder was used as a partial substitute for fine aggregates at the concentration of $5 \%, 15 \%, 30 \%$ and $50 \%$ (w/w of total aggregates), resulting in 90 specimens.

Table 1. Mix proportion of concrete with incorporation of GRP waste powder

\begin{tabular}{lllllll}
\hline \multirow{2}{*}{$\begin{array}{l}\text { Experimental } \\
\text { trials }\end{array}$} & \multicolumn{3}{c}{ Fine Aggregate } & \multirow{2}{*}{$\begin{array}{l}\mathrm{NCA} \\
\left.\mathrm{kCR} / \mathrm{m}^{3}\right)\end{array}$} & $\begin{array}{l}\text { Cement } \\
\left(\mathrm{kg} / \mathrm{m}^{3}\right)\end{array}$ & w/c ratio \\
\cline { 2 - 4 } & $\mathrm{NFA}$ & \multicolumn{2}{c}{$\mathrm{GRP}$ powder } & & \\
\hline 1 & 750 & 0 & 0 & 1250 & 430 & 0.50 \\
2 & 712 & 38 & 5 & 1250 & 430 & 0.55 \\
3 & 637 & 113 & 15 & 1250 & 430 & 0.57 \\
4 & 525 & 225 & 30 & 1250 & 430 & 0.68 \\
5 & 337 & 337 & 50 & 1250 & 430 & 0.71 \\
\hline
\end{tabular}

NFA: Normal Fine Aggregate

NCA: Normal Coarse Aggregate

W/C: Water-cement ratio

Control concrete specimens that contained no GRP waste powder were also casted to compare their properties over the GRP waste admixed concrete. Figure 2 and Figure 3 show the different stages of mixing of aggregates with GRP waste powder and the resulting GRP waste concrete cube and cylinder specimens respectively. 
Osmani, M. (2013) Innovation in cleaner production through waste recycling in composites, Management of Environmental Quality, 24(1), pp.1-9.

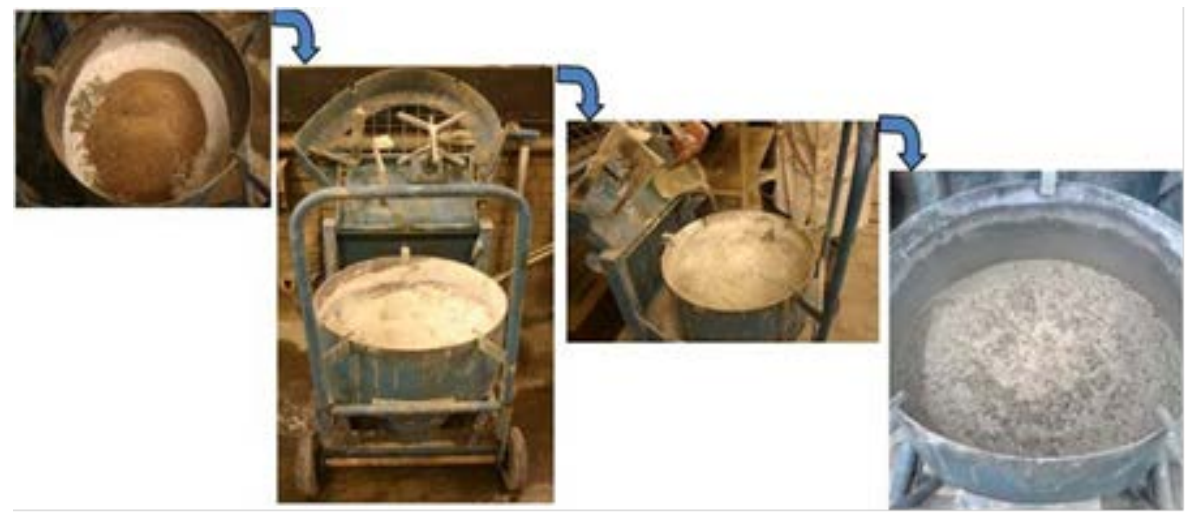

Figure 2. GRP waste-concrete mixing process

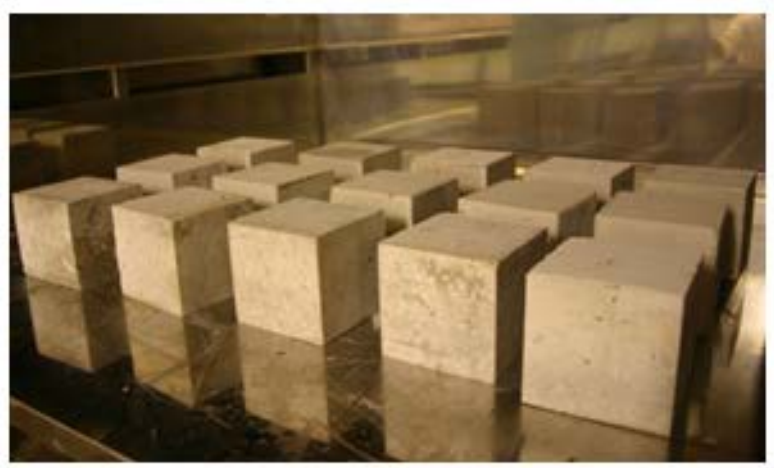

(a)

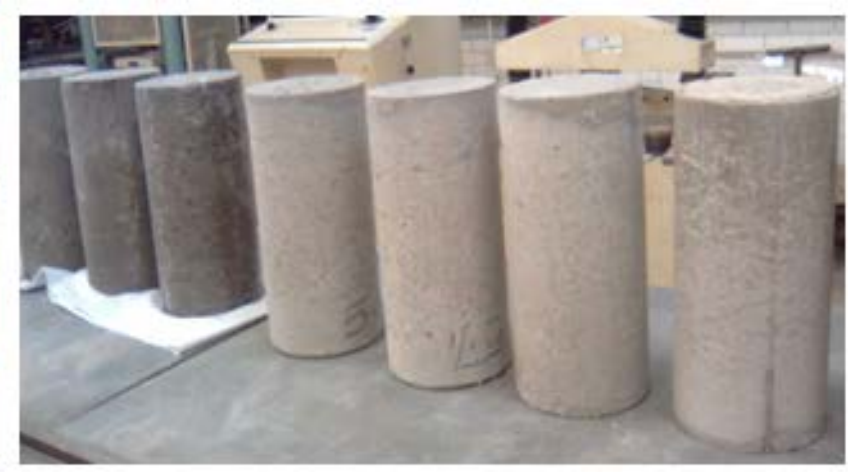

(b)

Figure 3: GRP waste-concrete mixing process

Compressive strength at 28 days and 180 days of the developed $100 \times 100 \mathrm{~mm}$ GRP waste powder concrete cubes was tested as per the specifications and procedure laid out in BS EN 12390-3:2002. Compressive strength is the capacity of a material or structure to withstand axially directed pushing forces. Additionally, split tensile strength of cylindrical GRP waste powder concrete samples, which conformed to EN 316, was assessed. Splitting tensile tests involve compressing a concrete cylinder on its side until a crack forms down the middle, causing failure of the specimen.

\subsection{GRP waste-cement composites experimental programme}

The aim of the second set of experiments was to explore the potential use of GRP waste fibre in cement composites. Two different cement composite panel sizes $(300 \mathrm{~mm} \times 300 \mathrm{~mm} \times 8 \mathrm{~mm}$ and $300 \mathrm{~mm} \times 300 \mathrm{~mm} \times 12 \mathrm{~mm})$ were prepared in accordance with the British Standard on fibre-cement flat sheets product specification and test method (BS EN 12467). In each panel, 5\% of GRP waste fibre (w/w of cement content) was premixed with mortar (1:1.6 cement to sand ratios) 
Osmani, M. (2013) Innovation in cleaner production through waste recycling in composites, Management of Environmental Quality, 24(1), pp.1-9.

along with 2\% superplasticiser (Polycarboxylate). Control cement composite specimens that contained no GRP waste fibre were also developed.

Figure 4 and Figure 5 show the different stages of mixing of aggregates with GRP waste fibre and the resulting GRP waste-cement panels.

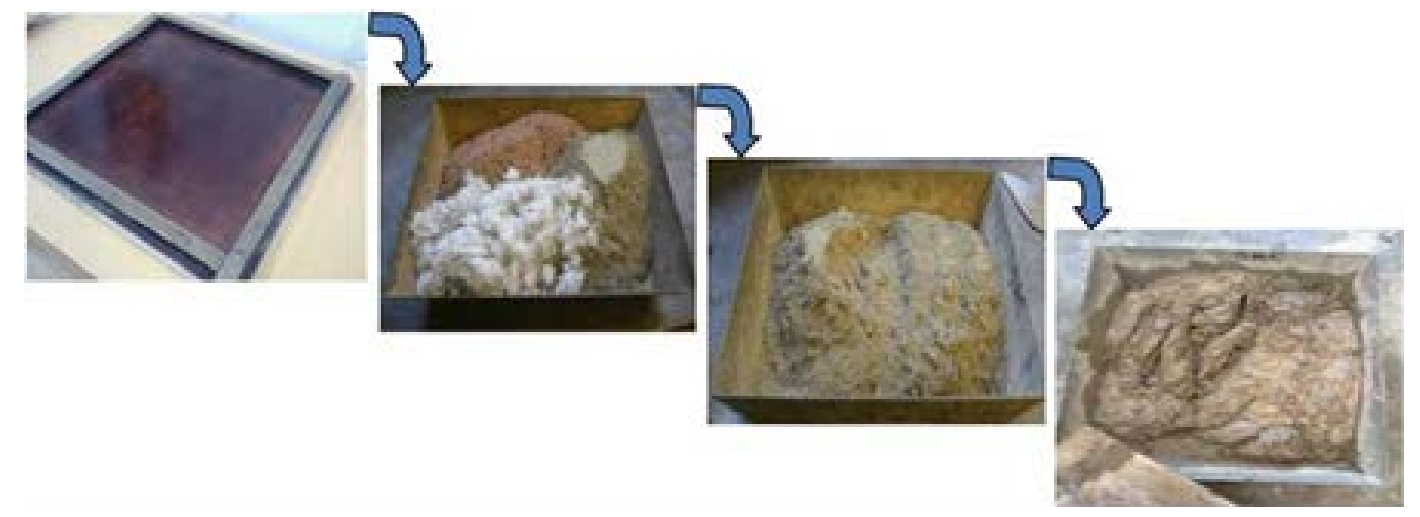

Figure 4: GRP waste fibre in architectural cladding panels: mixing process and resulting specimen
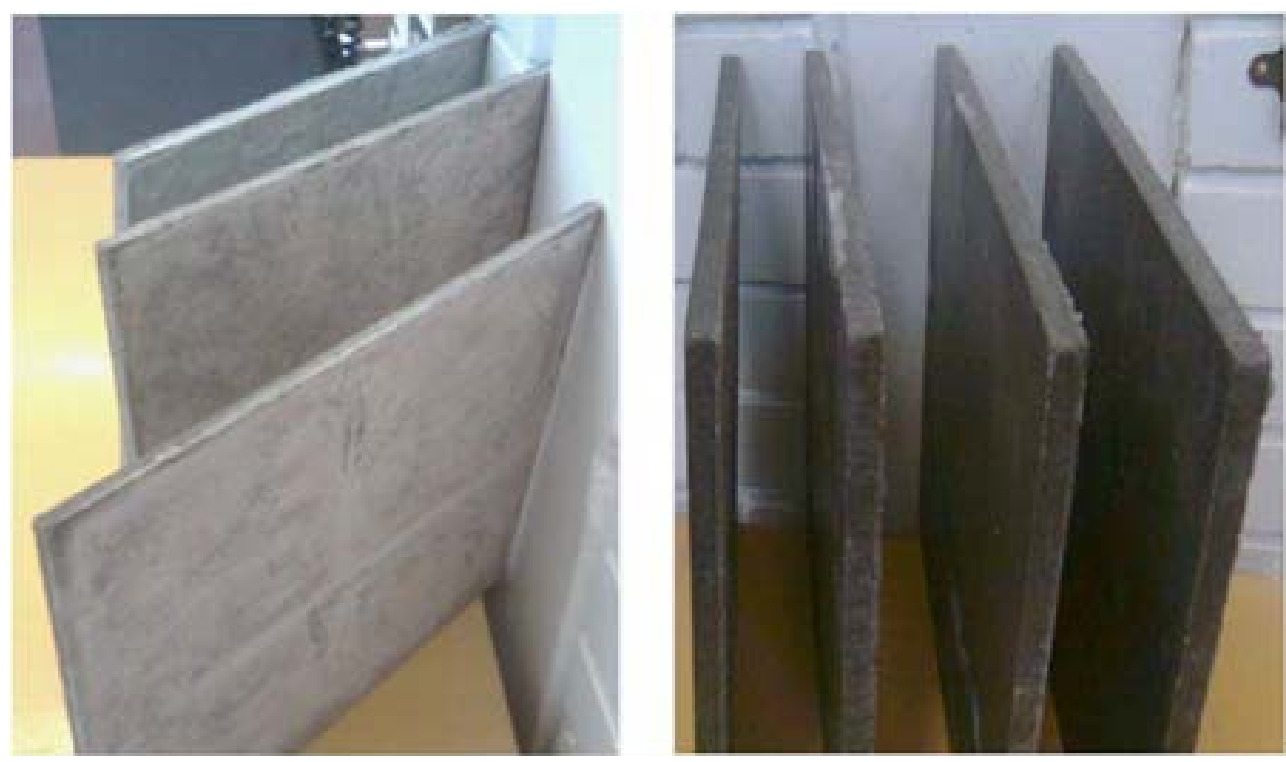

Figure 5: GRP waste fibre in architectural clading panels: resulting specimen

To assess the resulting panels' mechanical characteristics, the bending strength, which is the ability to resist failure in bending, also known as 'flexural strength'; and density, which is a measure of its unit weight that varies depending on the amount and density of the aggregate, the amount of entrained air (and entrapped air), and the water and cement content were tested (to comply with British Standard (BS EN 12467). 
Osmani, M. (2013) Innovation in cleaner production through waste recycling in composites, Management of Environmental Quality, 24(1), pp.1-9.

\subsection{GRP waste-rubber composites experimental programme}

GRP waste powder was mixed with natural rubber in a Haake Polylab system mixer to produce sample compounds. A total of up to 30 samples were prepared where GRP waste powder was used as a partial substitute for virgin rubber at the concentration of $5 \%, 25 \%$, and $50 \%(\mathrm{w} / \mathrm{w})$. Control rubber specimens that contained no GRP waste powder were also prepared to compare their properties over the GRP waste admixed rubber composites. A Polylab Monitor computer software was used for controlling the mixing conditions and storing data.

Figure 6 shows the different stages of mixing of natural rubber with GRP waste fibre.

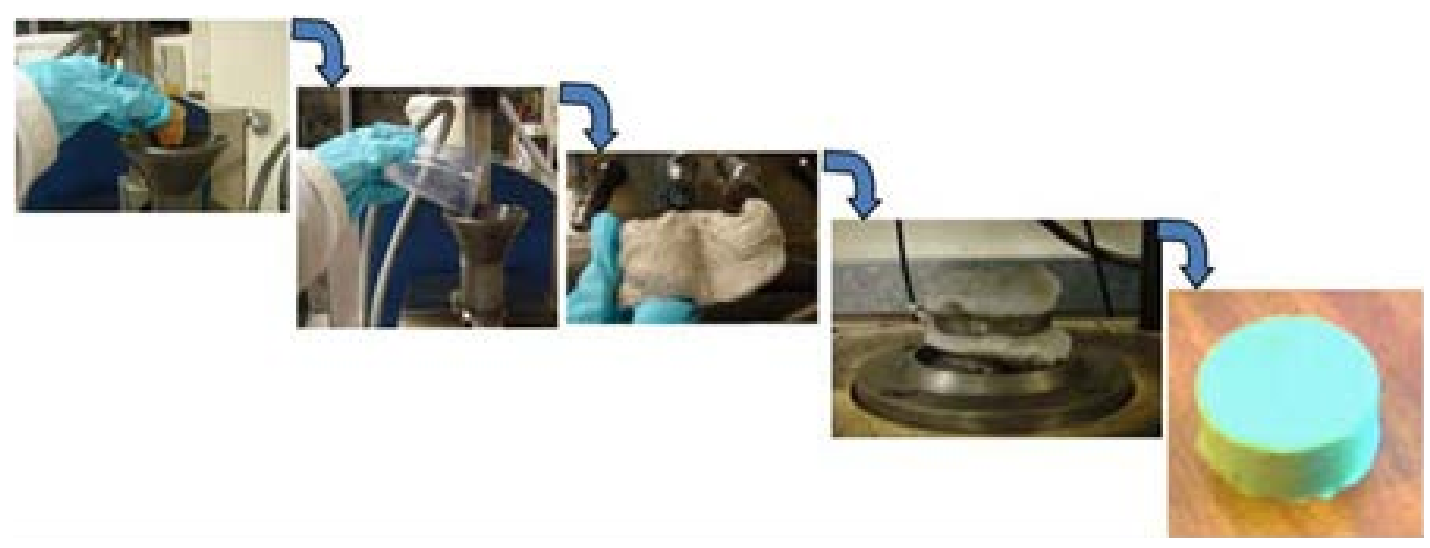

Figure 6: GRP waste-rubber mixing process

Cylindrical samples ( $12 \mathrm{~mm}$ thick and $28 \mathrm{~mm}$ in diameter) were produced to measure the hardness of the resulting waste-rubber composites. The samples were placed in a Shore A durometer hardness tester and the hardness of the rubber was measured at $22.5^{\circ} \mathrm{C}$ over a 15 -second interval after which a reading was taken. This was repeated at three different positions on the sample, and median of the three readings calculated.

The 'loss tangent (tan $\delta$ )' was measured in dynamic mechanical analyser DMAQ800, using Universal Analysis 2000 Software (Version 4.3A). Tan $\delta$ is the ratio between loss modulus and elastic modulus. The loss modulus represents the viscous component of modulus and includes all the energy dissipation processes during dynamic strain. Test pieces $34 \mathrm{~mm}$ long, $12 \mathrm{~mm}$ wide and approximately 2.7 $\mathrm{mm}$ thick were used. The tests were performed at $1 \mathrm{~Hz}$ frequency.

\section{Results and discussion}

\subsection{GRP waste powder-concrete composites}

\subsubsection{Compressive strength of GRP waste powder-concrete composites}

Results revealed that the 28 days mean compressive strength of concrete made with $5 \%$ GRP waste powder attained $37 \mathrm{~N} / \mathrm{mm}^{2}$ with standard deviation of 0.77 . However, the compressive strength of control concrete specimens showed the 
Osmani, M. (2013) Innovation in cleaner production through waste recycling in composites, Management of Environmental Quality, 24(1), pp.1-9.

optimum strength of $47 \mathrm{~N} / \mathrm{mm}^{2}$. The expected compressive strength of structural concrete is $45 \mathrm{~N} / \mathrm{mm}^{2}$. These results are in line with the work reported earlier where the influence of polymer latex on the properties of cement concrete showed that there was a decrease in compressive strength of concrete about $32 \%$ with addition of $10-20 \%$ polymeric materials. The present investigation showed that there was a decrease of compressive strength of concrete about $21 \%$ and $27 \%$ with an increase of $5 \%$ and $15 \%$ GRP waste respectively. However, the research revealed that compressive strength of GRP waste powder filled concrete increased considerably with longer curing periods. This was confirmed while comparing the compressive strength of concrete tested under different curing period from 14 days to 180 days. As shown in Table 2, the mean compressive strength of concrete developed using $5 \%$ and $15 \%$ GRP waste powder under 180 days curing was $45.74 \pm 0.76 \mathrm{~N} / \mathrm{mm}^{2}$ and $44.38 \pm 0.42 \mathrm{~N} / \mathrm{mm}^{2}$ respectively. On the other hand, the compressive strength of control concrete specimens (without GRP waste powder) at 180 days and 28 days remained relatively unchanged.

Table 2: Compressive strength of GRP waste powder-concrete composites (in $\mathrm{N} / \mathrm{mm}^{2}$ )

\begin{tabular}{ccccc}
\hline $\begin{array}{c}\text { Exp } \\
\text { No. }\end{array}$ & $\begin{array}{c}\text { GRP } \\
\text { Powder } \%\end{array}$ & 14 Days & 28 Days & 180 days \\
\hline 1 & $0 \%$ & $43.61 \pm 0.37$ & $47.67 \pm 0.69$ & $46.23 \pm 0.57$ \\
\hline 2 & $5 \%$ & $32.4 \pm 0.86$ & $37.08 \pm 0.77$ & $45.74 \pm 0.69$ \\
\hline 3 & $15 \%$ & $27.95 \pm 0.25$ & $34.09 \pm 0.90$ & $44.38 \pm 0.42$ \\
\hline 4 & $30 \%$ & $22.4 \pm 1.12$ & $29.58 \pm 1.66$ & $30.82 \pm 0.64$ \\
\hline 5 & $50 \%$ & $14.13 \pm 0.59$ & $19.05 \pm 0.88$ & $21.31 \pm 0.03$ \\
\hline
\end{tabular}

A study by Jo et al (2003) showed that application of 9\% polyester resin (virgin materials) in recycling unsaturated polyester resins from recycled polyethylene terephthalate (PET) plastic waste and recycled concrete aggregates with normal fine and coarse aggregate up to $70 \%$ attained a compressive strength of $39 \mathrm{~N} / \mathrm{mm}^{2}$. It was expected that the glass fibre content in GRP waste may contribute to increase the reinforcement of concrete. Conversely, the work done by Taha and Nounu, (2008) revealed that no significant results were recorded on the compressive strength of concrete developed with recycled glass and about $16 \%$ strength was reduced when $20 \%$ of Portland cement was substituted. This was due to the inherent smooth surface, poor water absorption and contamination of raw materials which resulted in inconsistency of the concrete mix, lack of bonding between glass particle and cement matrix leading to low compressive strength. Since, polymerisation temperature ranges from $40^{\circ} \mathrm{C}$ to $110^{\circ} \mathrm{C}$ in this research, cement metric and GRP waste powder blend together and were casted as solid monolithic structure and cured in $50^{\circ} \mathrm{C}$ in which it was expected to form polymeric film contributing to increase in the compressive strength of concrete when compared to water cured samples. Hence, the present study explored possible recycling options to improve the quality of concrete with applications of GRP waste powder. It was anticipated that the presence of ground glass fibre in GRP waste may contribute to an increase of concrete reinforcement. 
Osmani, M. (2013) Innovation in cleaner production through waste recycling in composites, Management of Environmental Quality, 24(1), pp.1-9.

Glass powder can be used as replacement for cement up to $10 \%$ to increase the compressive strength of concrete (Schwarz et al, 2008). The presence of polymer particles in the dispersion is restricted to the capillary force at the interface of the aggregate and the bulk polymer-cement phase and the polymer products included in these hydration products do not contribute to the strength development. This has been further supported with the results of (Gemert et al, 2005) who reported that no influence of polymer modification on the strength was noticed in standard cured and water cured specimens as long as they are not dry cured. This suggests that the polymeric powder in the GRP waste might have degraded from its virgin resin characteristics; and hence, the presence of polymeric compound in GRP waste powder might have not contributed to enhance the compressive strength. However, the present investigation revealed that the compressive strength of concrete specimens developed using GRP waste powder found to be higher than that of the normal requirement for precast concrete walling element $(>5 \mathrm{MPa})$, light weight concrete ( $>5 \mathrm{MPa}$ ), and concrete blocks (7 to $35 \mathrm{MPa}$ ) and confirmed the potential applications of GRP waste as an additive or filler in concrete.

\subsubsection{Tensile split strength of GRP waste powder-concrete composites}

The tensile splitting strength of normal concrete is $3.9 \mathrm{~N} / \mathrm{mm}^{2}$. Results of the present study revealed that the mean tensile splitting strength of concrete attained 4.12 $\mathrm{N} / \mathrm{mm}^{2}$ and $4.22 \mathrm{~N} / \mathrm{mm}^{2}$ with $5 \%$ and $15 \%$ GRP waste powder respectively. It is interesting to note that the tensile splitting strength of concrete developed with $5 \%$ and $15 \%$ GRP waste powder was higher than that of the control concrete specimens (with no GRP waste powder) which measured $3.85 \mathrm{~N} / \mathrm{mm}^{2}$.

The improvement of the tensile splitting strength may be due to presence of glass fibre and retardation of the cement hydration. Furthermore, due to the interaction between the cement matrix and polymeric powder, the split tensile strength of binder matrix and adhesion strength between the aggregate and binder might have increased. Numerous studies were conducted to assess the mechanical properties of fibre reinforced polymer concrete, but, data on its tensile properties is still lacking. Moreover, the mean tensile splitting strength attained from the present study with GRP waste powder complies with the British Standard specification for use in structural applications. It is apparent from these results that the presence of chemical constituents in GRP waste powder and the synergetic effect significantly contributed to improving the quality of concrete. Beeldens et al, 2003 reported that waste glass was used in concrete as aggregate but its applications were limited due to their expansion characteristics and alkali silica reaction. In order to confirm the environmental significance of GRP waste admixed concrete, further studies are recommended to assess the impact of GRP waste on the alkali silica reaction in concrete.

\subsection{GRP waste-cement composites}

\subsubsection{Bending strength of GRP waste-cement composites}

The effect of GRP waste fibre on the bending strength of cement composites revealed that the mean bending strength in terms of modules of rupture (MOR) of $8 \mathrm{~mm}$ and $12 \mathrm{~mm}$ thick panels developed using 5\% GRP waste fibre attained 8.88 $\mathrm{N} / \mathrm{mm}^{2}$ and $16.55 \mathrm{~N} / \mathrm{mm}^{2}$ respectively. It is interesting to note that the application of 
Osmani, M. (2013) Innovation in cleaner production through waste recycling in composites, Management of Environmental Quality, 24(1), pp.1-9.

5\% and 15\% GRP waste fibre increased the bending strength of architectural cladding panels over control specimens by $25 \%$ and $36 \%$ respectively. This research revealed that the application of GRP waste fibre has improved the bending strength and reduced the crack propagation of the cement composites. On the other hand, the control specimens (without GRP waste fibre) showed multiple cracks and low bending strength. Cement composite panels developed by Marley Eternit using vacuum spray manufacturers' process showed that the bending strength of cladding panels developed using virgin glass fibre varies from $17 \mathrm{~N} / \mathrm{mm}^{2}$ to $24 \mathrm{~N} / \mathrm{mm}^{2}$ (Marley Eternit, 2011).

\subsubsection{Density of GRP waste-cement composites}

The mean density of $12 \mathrm{~mm}$ thick cement composites developed using 5\% GRP waste fibre was $18 \%$ higher than that of control specimens. Similarly, the mean density of $8 \mathrm{~mm}$ thick panels developed with 5\% GRP waste fibre was 15\% higher as compared to control samples. Since the density of glass fibre varied from 2540 $\mathrm{kg} / \mathrm{m}^{3}$ to $2780 \mathrm{~kg} / \mathrm{m}^{3}$, addition of $5 \%$ GRP waste fibre in cement composites might have contributed to increase the density of panels. Moreover, application of superplasticiser reduced the water content and contributed towards more compaction and increased the quantity of cement composites leading to higher density. The mean density of $8 \mathrm{~mm}$ panels developed without GRP waste fibre was $1668 \mathrm{~kg} / \mathrm{m}^{3}$.

\subsection{GRP waste-rubber composites}

\subsubsection{Mechanical properties of GRP waste-rubber composites}

The mechanical properties of GRP waste-rubber composites were affected differently by the inclusion of the GRP waste powder in the rubber. The hardness was unchanged at 45-46 Shore A when up to 25\% of GRP powder was added, and it increased to 51 Shore A as the concentration of the GRP powder was raised to $50 \%$.

Similarly, the Young's modulus rose from 1.2 to 1.8 MPa when the full loading of the GRP powder was incorporated in the rubber, and continued to rise with the increase of GRP powder. For example, at $50 \%$ strain amplitude, the modulus increased by $75 \%$ with 50\% GRP powder addition. Evidently, the modulus benefited from increases in the loading of the GRP powder, irrespective of the level of strain on the rubber, but was adversely affected by increases in the level of strain on the rubber at a given loading of the GRP powder.

\subsubsection{Thermal and acoustic properties of GRP waste-rubber composites}

Figure 7 shows tan $\delta$ as a function of temperature for the GRP waste-rubber composites containing $0 \%, 5 \%, 25 \%$ and $50 \%$ GRP waste powder. Tan $\delta$ is a measure of energy dissipation in the rubber. For the control rubber specimens, $\tan \delta$ decreased from 0.02 to 0.01 as the temperature was increased to $100^{\circ} \mathrm{C}$. When $5 \%$ GRP waste powder was added, tan $\delta$ increased by a factor 2 . 
Osmani, M. (2013) Innovation in cleaner production through waste recycling in composites, Management of Environmental Quality, 24(1), pp.1-9.

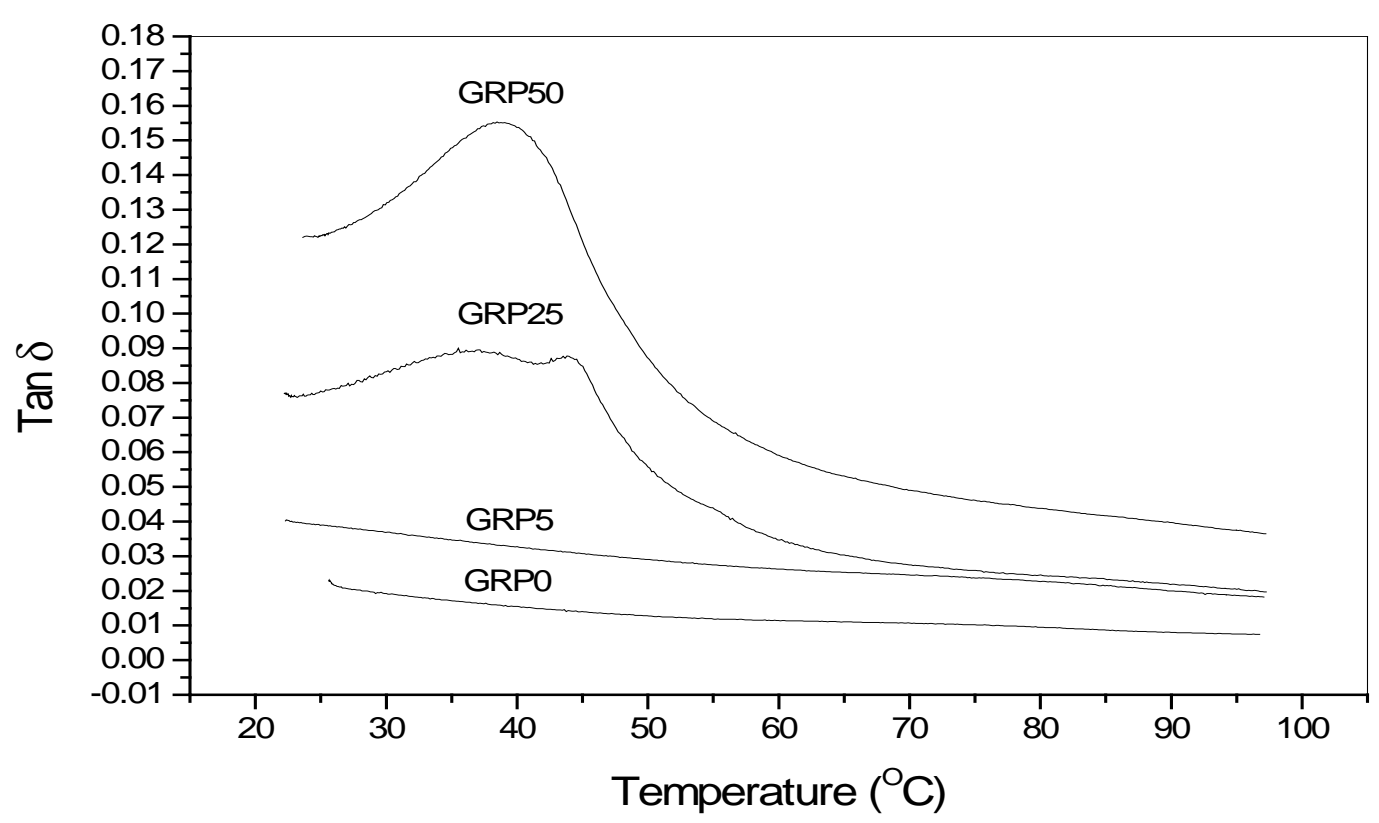

Figure 7: Tan $\delta$ versus temperature of GRP waste-rubber composites containing $0 \%, 5 \%, 25 \%$ and $50 \%$ GRP waste powder

Interestingly, adding 25\% GRP waste powder raised the tan $\delta$ values to 0.09 for up to $45^{\circ} \mathrm{C}$ and then it decreased sharply to 0.04 . The largest effect was observed for specimen with $50 \%$ GRP waste powder concentration. Tan $\delta$ rose to 0.16 as the temperature was increased to $40^{\circ} \mathrm{C}$. It then decreased to 0.04 as the temperature was raised to $100^{\circ} \mathrm{C}$. Clearly, the addition of GRP was beneficial to the energy dissipation processes in the rubber. This in turn improved the acoustic properties by enabling the GRP waste-rubber composites to absorb and dissipate acoustic energy in the rubber.

\section{Conclusions}

The findings of this research pave the way for viable technological options for substituting quality raw materials by GRP waste in pan-industry composites and improving their mechanical properties. Results indicated that concrete composites at 28 days curing period and developed with $5 \%$ to $15 \%$ substitution of fine aggregates by GRP waste powder could be used for semi-structural concrete products. However, the research demonstrated that GRP waste powder-filled concrete composites at a curing period of 180 days could be specified as structural elements in construction. Furthermore, results showed that the addition of GRP waste powder increased the splitting strength of concrete, complies with the British Standard specification for use in structural applications, and can also be used as an additive or filler in concrete. Similarly, GRP waste fibre increased significantly the bending strength and density of cement composites. Equally, GRP waste powder improved the stiffness and acoustic performance of rubber composites, could replace up to $50 \%$ of virgin rubber, and may be used as extender filler in industrial rubber compounds. That said, full compliance tests such as durability and fire properties for specific composite applications are recommended. It is anticipated that the findings of this research would help diverting GRP waste from landfill to higher grade industrial applications. 
Osmani, M. (2013) Innovation in cleaner production through waste recycling in composites, Management of Environmental Quality, 24(1), pp.1-9.

\section{Acknowledgements}

The authors are thankful to the UK Technology Strategy Board and the project industrial partners for funding this research (Project No: TP/3/WMM/6///16112). Thanks are extended to the technicians and supporting staff at Loughborough University, UK (Material and CBE Laboratories) for the technical support.

\section{References}

Ansarifar, A.., Wang, L., K. K. Yoong, Osmani, M and Pappu, A. (2010)

"Characterisation and use of glass fibre reinforced plastic waste Powder as filler in styrene-butadiene rubber", Journal of Rubber Research, Vol.13 No. 3, pp. 162-174.

Beeldens A, Gemert VD, Ohama Y, Czarnecki L. (2003), “Integrated model of structure

formation in polymer modified concrete", Proceedings of the $11^{\text {th }}$ International Congress on the Chemistry of Cement, Durban.

Bentur A and Mindess S. (1990), Fibre Reinforced Cementitious Composites, Elsevier Science Publishers Ltd, London.

Broekel J and Scharr G. (2005), "The specialities of fibre-reinforced plastics in terms of product lifecycle management", Journal of Materials Processing Technology, Vol.162-163, pp.725-729.

Conroy A, Halliwell S, Reynolds T. (2006), "Composite recycling in the construction industry", Composites Part A: Applied Science and Manufacturing, Vol.37 No.8, pp.1216-22.

Gemert DV., Czarnecki L, Maultzsch M, Schorn H, Beeldens A, Łukowski P, Knapen E. (2005), Cement concrete and concrete-polymer composites: Two merging worlds, A report from 11th ICPIC Congress in Berlin. Cement \& Concrete Composites, Vol.27, pp. 926-933.

Jo BW, Park SK, Park J.C., (2008), "Mechanical properties of polymer concrete made nwith recycled PET and recycled concrete aggregates", Construction and Building Materials, Vol. 22 No.12, pp.2281-2291.

Jones, M., Mccarthy, A. and Dhir, R. (2005), Recycled and secondary aggregates in foamed concrete, DTI/WRAP Aggregates Research Programme STBF13/13C, ISBN: 1-84405-184-6.

Khan R. (2007) Industry survey on production availability and cost of GRP waste in the UK, Hambleside Danelaw Rooflights and Cladding Limited, Inverness, Scotland.

Marley Eternit (2011) "Home page", available at:

http://www.marleyeternit.co.uk/Cladding.aspx (accessed 30 November 2011)

Ord G. (2011) "New milling technology has potential to open up new recycling markets", available at: http://iituk.com/news 04.php (accessed 13 December 2011).

Schwarz N, Cam H, Neithalath N.( 2008), "Influence of a fine glass powder on the 
Osmani, M. (2013) Innovation in cleaner production through waste recycling in composites, Management of Environmental Quality, 24(1), pp.1-9.

durability characteristics of concrete and its comparison to fly ash", Cement \& Concrete Composites, Vol. 30, pp. 486-496. 